\title{
THE FOSSIL CRINOID GENUS VASOCRINUS LYON
}

\author{
By EDwin Kirk \\ of the United States Geological Survey
}

The present paper is not in the nature of another revision of the genus Vasocrinus Lyon, but rather the purpose is to reestablish the genus on the foundations originally laid by its author. In doing this, to be sure, it will be necessary to revise Lyon's somewhat crude and incorrect descriptions in important details. Through the kindness of the late Dr. Frank Springer, in whose collection in the United States National Museum Lyon's original types now are, I have had opportunity to study all of Lyon's material, together with other specimens referable to the genus. As first examined Lyon's types were found with the cup plates outlined in ink, presumably for the guidance of the draftsman. As marked the plates conformed to Lyon's descriptions. A casual inspection of the specimens, however, showed that as regards the plates of the posterior interradius Lyon had erred in his interpretation of the cup structure. The same material is here refigured and the true structures shown and described. In addition information has been obtained in regard to the structure of the tegmen. It is now found that Vasocrinus as based on Lyon's own species is a quite different crinoid from what has generally been supposed.

In considering the status of the genus Vasocrinus all references subsequent to 1879 may be ignored. In their "Revision" ${ }_{1}$ (pp. 94-96 (319-321)) Wachsmuth and Springer chose Cyathocrinus tyoni Hall, which is a synonym of Cyathocrinus hexadactylus Lyon and Casseday, as type of the genus. They say (p. 95) : "In reconstructing the genus we prefer to make Vasocrinus Lyoni (Cyathocrinus Lyoni Hall), from Crawfordsville, the type, because it is found more perfectly preserved in the arm portion; but we scarcely doubt, to judge from the brachials, as far as they are preserved, that the arms in the Devonian species were constructed in a like manner." This generic conception of Vasocrinus as modified by Wachsmuth and Springer has

\footnotetext{
1 Wachsmuth, Charles, and Springer, Frank, Revision of the Palaeocrinoidea, Part 1, Acad. Nat. Sci. Philadelphia Proc. for 1879, pp. 226-378 (author's separate pp. 1-153), pls. $15-17$.
} 
been the one accepted by subsequent authors. In no case has Lyon's original material been studied except by Wachsmuth and Springer. The genus then as defined and discussed by various authors has been the Vasocrinus of Wachsmuth and Springer and not the Vasocrinus of Lyon. Cyathocrinus hexadactylus Lyon and Casseday (Cyathocrinus lyoni Hall), which was chosen by Wachsmuth and Springer as genotype of Vasocrinus, can not be retained. Such a procedure exceeds the somewhat elastic bounds permitted subsequent authors in designating a genolectotype. Vasocrinus was founded by Lyon to take care of the two Devonian species valens and sculptus and the transfer of the genus to a Carboniferous species which by no chance is congeneric with either of the original species is scarcely admissible. In rejecting Vasocrinus as represented by the structures found in Cyathocrinus hexadactylus Lyon and Casseday I am forced back to a consideration of Lyon's original species. For the reception of Cyathocrinus hexadactylus Lyon and Casseday (Cyathocrinus Tyoni Hall) it is necessary to create a new genus, for which the name Pellecrinus is here proposed.

In 1857 Sidney S. Lyon ${ }^{2}$ described and figured the new genus $V$ asocrinus, referring to it two new species, $V$. valens and $V$. sculptus. This report is.now somewhat difficult to obtain. The plates illustrating the paleontologic part of the report were distributed in a separate atlas with cardboard covers. This atlas is even rarer than the report. As the plates of the atlas are not bound in, sets are seldom complete. For these reasons it has seemed best to republish Lyon's original descriptions in full and to reproduce the original figures as well. As Lyon's figures will frequently be referred to and the individual specimens designated by the numbers appearing on Lyon's plate the figures as here shown on Plate 1, Figure 10, are given the same numbers and letters used by Lyon. In his descriptions Lyon used three specimens. It is essential that the identity of each of these be kept in mind, for as will be shown one of these specimens ( $3 b$ ) seems to have been referred originally to $V$. valens by Lyon and used in the description of that species by him, although subsequently identified as V. sculptus. A transcription of Lyon's text and his explanations of the $V$ asocrinus figures on the plate are here given.

[TEXT, PAGES 485-487]

\section{Genus VASOCRINUS Lyon}

Gen. char.-Body vase shaped; twice as wide as high; basal pieces five; pentagonal; pointed at their superior margin; primary radials five; rising between the points of the basal pieces; secondary radials five; broad; irregu-

${ }^{2}$ Lyon, S. S., in Owen, D. D., Third Report of the Geological Survey in Kentucky, pp. $485-487$, pl. 4 , figs. $3,3 a-d, 1857$. 
larly pentagonal; arms five; single; composed of cylindrical pieces; anal piece one; hexagonal; large; summit unknown; column unknown.

\section{VASOCRINUS VALENS Lyon}

(Plate IV, Figures $3,3 a$ )

Basal pieces, five; low, broad; pointed at their summit; swelling at the base; forming a shallow cup, with perpendicular sides; bottom slightly concave; superior margin divided by obtuse points into five broad, shallow, angular notches; the base articulates with the column by a surface marked by striae, radiating from a small circular opening.

Radial pieces, five; smooth; subhexagonal; differing slightly in size; higher than wide; rising between the basal pieces.

Secondary radials, five in number; smooth; pentagonal; nearly twice as wide as high; the median line of these pieces are nearly horizontal; the truncated face, for the insertion of the arms, elliptical, concave, perforated near the center, deeply sulcate above the perforation; the sides are joined together, curving upward and terminating on the summit between the arms; the piece on the left of the anal piece is much larger than either of the others, and covers the points of two of the radials, whilst that on the right of it is smaller than the others and rises from the point and left side of the primary radial, beneath it. The anal piece is large, subhexagonal, rising between two of the primary radials, and extends above the lower margin of the axillary face of the second primary radials.

Arms composed of cylindrical pieces, their length and diameter being nearly equal; perforated and deeply sulcate on the superior side.

Dimensions :

Diameter of the base 0.45 inch.

Height of the base 0.27 inch.

Height of the body 0.55 inch.

Greatest diameter 1. 05 inches.

Diameter of the axillary articulation 0.27 inch.

Remarks.-This remarkable crinoid was obtained several years since at the quarries on Beargrass Creek, near Louisville, where it was found associated with Actinocrinus, Dolatocinus, etc. It is very rare-this specimen is the only one of this species heretofore obtained.

\section{VASOCRINUS SCULPTUS Lyon}

(Plate IV, Figures $3 b, 3 c, 3 d, 3 e$ )

Body small; vase shaped; section at the junction of the arms pentagonal; side of pentagon above the anal pieces nearly twice as long as either of the others; the surface is roughened by raised sculpture; the center of the pieces below the arms are all prominent. On either side of the sutures marking the junction of the basal pieces is a raised rib, which terminates at the center of the first radial pieces lying above the sutures. Similar ribs cover the body, extending from near the center of each to the center of all the contiguous pieces (except the basal pieces), thus dividing the surface into nearly equal-sided triangular spaces, deeply depressed at the center, and curving up to the ribs whicb define them; at the end of the ribs the triangular spaces are joined by a narrow grooved avenue, not quite so deep as the center of the spaces. 
Basal pieces five; pentagonal; as high as wide; extending beneath to the columnar perforation; junction with the column slightly concave.

Radial pieces five; hexagonal; four of equal size; as high as wide; one much larger than the others, rising between the points of the basal pieces.

Secondary radials (scapulae, Miller) five; irregularly pentagonal; nearly equal in size, except the piece on the left of the anal pieces, which is nearly twice as large as either of the others; articulating facet of the arms uneven; perforated; sulcated upon the upper side; the pieces curve upward at their line of junction, and terminate upon the summit above the line of the arms.

Anal pieces two; hexagonal; one equaling in size the first radial pieces; the other is quite small.

Arms five; single; structure beyond the first joint unknown; they start from the body in a horizontal direction.

Column unknown.

Geological position and locality.-Found in the limestone about 5 feet beneath the Devonian black slate, and above the beds of Hydraulic cement stone, Jefferson County, and in the same geological position on the falls of the Ohio. It does not appear, from what is known of it, to have a very great vertical range, probably not more than 3 or 4 feet.

[“EXPLANATION OF THE PLATES," PAGE 497]

Vasocrimus valens Lyon

Volume 3, page 485

FIg. 3. Generic figure, size of nature, the pieces arranged around the columnar facet.

Fig. $3 a$. Profile view, Vasocrinus valens.

Fig. $8 b$ (in error for $3 b$ ). Vasocrinus sculptus, from which the external sculpture has been removed, anal side front, natural size.

Vasocrinus sculptus Lyon

Fig. $3 c$. Profile view, natural size, different specimen.

Fig. $3 d$. Basal view of same specimen.

FIg. $3 e$. Summit view of same specimen, natural size.

Legend at bottom of Plate IV

FIG. 3. Vasocrimus, Generic figure.

FIG. 3a. Vasocrinus valens.

FIg. $3 b$. V. sculptus different specimen basal view.

Fig. 3c. V. sculptus profile view.

Fig. $3 d$. View of crown.

Fig. 3e. Basal view.

In regard to specimen $3 a$ Lyon says (p. 486): "It is very rarethis specimen is the only one of this species heretofore obtained." Lyon's figure shows this specimen in an inverted position and as viewed probably from the anterior radius. As figured the cup appears to be perfect, and so would one judge from the description. As a matter of fact the specimen is a weathered dorsal cup, well preserved so far as it goes, but lacking two radials and the entire 
posterior interradius. There is no reason to believe that the cup was more perfect in Lyon's day than now. The broken margin of the cup is weathered, and nowhere is there a sign of fresh fracture. There can be no question as to the identity of the specimen. It bears a piece of paper with a printed number (in this case 119) such as is found on all of Lyon's specimens. There is also an inked " $3 a$ " on the specimen, referring to the figure on his plate, and the plates of the cup are outlined with ink in the same manner as other figured specimens in his collection. It is evident that the fourth and fifth radials shown in the background of his figure were supplied by the draftsman. The description of the posterior interradius and the generic diagram presumably based on this specimen were made from specimen $3 b$ as will be shown hereafter. Although said by Lyon to be the only specimen of the species known, $3 a$ is here made a cotype of the species. Specimen 3b, referred by Lyon to $V$. sculptus, is made a companion cotype. As will be shown specimen $3 b$ was used by Lyon in his description of valens and is almost certainly referable to that species.

Specimen $3 b$ as studied by Lyon was partially embedded in a fragment of limestone, concealing the upper part of the posterior interradius. The specimen has been very badly treated. The infrabasals have been broken off and cemented on again. The portion of the cup extending from the 1 . post. $R$ across the post. IR and around almost to the ant. $R$. has been deeply gouged by a chisel or similar instrument, until little of the original surface remains. So badly defaced is the specimen that it is difficult to figure it in such a way as to give a correct idea of its original form. I have cleaned the higher part of the post. IR and lifted the entire specimen off the rock. In cleaning the specimen and to avoid mistakes the plate outlines as inked in by Lyon have been washed off. Lyon's number for this specimen was 119, the same as for the type specimen of $V$. valens. It appears that Lyon himself had originally referred this specimen to valens. In his explanation of the plate on page 497 this specimen appears under the title Vasocrinus valens, although assigned to $V$. sculptus, "from which the external sculpture has been removed." In the legend at the foot of the plate this specimen, although the first referred to sculptus, is described as "V. sculptus, different specimen basal view." From the crowding of the words and the wording itself I believe that Lyon had first referred this specimen to valens and had changed his mind after the plate had been engraved, erasing and changing the specific name from valens to sculptus. Even more striking proof is afforded by the figure itself and the specimen as originally marked. In the description both of valens and of the genus, as well as in the generic diagram, the posterior interradius agrees with Figure $3 b$ and with the specimen 
itself as originally marked in ink. The obviously artificial structures shown and described could scarcely have been independently invented and must have been based on the assumed plate arrangement in specimen 3b. Again Lyon had catalogued his collection, assigning a separate serial number to each species. These numbers were printed and the bits of paper glued to the specimens. Here we find as noted above that the same number (119) was affixed to both specimens $3 a$ and 3b. In Lyon's manuscript catalogue this number is identified as Vasocrinus valens. It appears, then, that the description of $V$. valens, the generic diagnosis, and the generic diagram were composited from specimens $3 a$ and $3 b$, although the latter was subsequently referred to the other species $V$. soulptus. In the present paper specimen $3 b$ is referred to Vasocrinus valens and made a cotype, despite Lyon's treatment, inasmuch as an essential part of his specific description is based on the specimen.

Specimen $3 c, d, e$ is in a good state of preservation although somewhat weathered. The tegmen is not preserved, but all the plates of the cup show clearly. Here again Lyon's plate outlines have been erased in order to mark them in properly. The specimen bears the printed serial number 120 . This specimen is here considered as the holotype of Vasocrinus sculptus Lyon.

We have seen that Lyon described two new species under his new genus Vasocrinus, basing his descriptions on three specimens, here identified by the numbers originally used by Lyon on his Plate $3 a$, $3 b$, and $3 c-e$, respectively. It now remains to determine the mutual interrelationships of the three specimens and choose a genotype for Vasocrinus. Lyon himself evidently based his generic description on $V$. valens. The generic diagnosis agrees best with the specific description of Vasocrinus valens, and Lyon himself (p. 485) cites the generic diagram as $V$. valens. The description of $V$. valens, however, was not made wholly from specimen $3 a$, in spite of Lyon's declaration elsewhere quoted that this was the unique specimen of the species. As noted above, this specimen is an imperfect dorsal cup, lacking the entire posterior interradius. Furthermore, no arm ossicles are shown in Figure $3 a$ nor are any attached to the specimen itself. Nevertheless, arm ossicles are described in the text. Lyon's generic diagram, Figure 3 , is obviously based primarily on specimen $3 a$, as shown by the size of the plates. As specimen $3 a$ lacks two radials and the posterior interradius, it is evident that the missing plates were obtained elsewhere. Such liberties are not unknown in the case of authors of later generations, unfortunately. The source of supply for these plates could only have been specimen Figure $3 b$. It will be noted that Lyon described his genus as having but one anal plate, though in his specific description of $V$. sculptus he notes the presence of two 
such plates. If one will attempt to reconstruct a dorsal cup from generic diagram Figure 3 he will find that an impossible crinoid structure results. Precisely such a structure is indicated in Figure 3b, and as I first saw it the specimen itself had the same curious grouping of malformed plates outlined on the surface in ink. What Lyon actually did was to coalesce 1 . post. $R$ with part of anal $x$. His large single anal plate and its remarkable shape was brought about by the coalescence of $\mathrm{R} A$ with part of anal $\mathrm{x}$, part of $\mathrm{r}$. post. $\mathrm{R}$, part of post. B, and all of $r$.

Were specimen $3 a$ the only individual referable to Vasocrinus valens, I would reject the species as genotype, despite the fact that it is the first species described and evidently was Lyon's own choice. Lacking as it does the essential posterior interradius, the status of the genus would forever be in doubt. To choose $V$. sculptus would be unwise. $V$. sculptus shows structural features sufficiently at variance with those of valens to raise a suspicion that when well preserved crowns are available for study the two species might not prove congeneric. Fortunately the matter is simplified by the discovery that specimen $3 b$, used by Lyon in his diagnosis of the genus and in the description of $V$. valens, can well be referred to that species. It can not by any chance be conspecific with specimen $3 c-e$. On the other hand, close comparisons of specimen $3 b$ after being freed from the matrix with specimen $3 a$ as well as other imperfect specimens clearly conspecific with $3 a$, but of smaller size, indicate the propriety or rather necessity of referring specimen $3 b$ to Vasocrinus valens. Furthermore, a well-preserved theca, clearly congeneric with valens, has come to light that not only shows all the plates of the dorsal cup, but has a well-preserved tegmen. With specimens $3 a$ and $3 b$ united under one species, most of our troubles are over. Now, the generic description of Vasocrinus and the description of $V$. valens are in complete harmony with the structures of the specimens referred to it-that is, the structure as interpreted by Lyon. The proper course, then, seems clearly to be to make Vasocrinus valens the genotype, transferring to the species specimen $3 b$.

\section{Genus VASOCRINUS Lyon}

In drawing up the formal definition of the genus Vasocrinus the type species $V$. valens Lyon and the closely allied $V$. turbinatus, new species, have been used. $V$. sculptus Lyon may be congeneric and so far as its structures are known can not well be separated from the genus. Its variations in structure from the typical forms have not, however, been incorporated in the generic description. Two new species from the Middle Devonian, one from the Hamilton of New York and the other from the Traverse formation of Michigan, are 
tentatively referred to Vasocrinus, but their ascription to the genus is not sufficiently certain to warrant their description in this paper.

Jaekel ${ }^{3}$ has proposed the new genus Costalocrinus with Poteriocrinus dilatatus L. Schultze as the genotype. Costalocrinus dilatatus does not have rt in the dorsal cup, but otherwise greatly resembles Vasocrinus. Among the described crinoids of the German Devonian, two species I think are certainly referable to Vasocrinus. These are Posteriocrinus stellaris L. Schultze and Parisocrinus canaliculatus Jaekel. It is of interest to note in this connection that the type of Vasocrinus stellaris (Schultze) has no rt, but a specimen considered by Jaekel as undoubtedly conspecific has three anal plates in the cup. Vasocrinus canaliculatus (Jaekel) appears to be very close to the typical form of Vasocrinus.

Generic diagnosis.-Dorsal cup subturbinate to somewhat bowlshaped. Plates relatively thin. Radials curving inward in their upper portions, forming a marginal platform around the periphery of the tegmen, except in the posterior interradius. Arm facets broadly horseshoe shaped, with the axial canal typically separate from the food groove. There is a tendency toward the suppression of the food groove in the anterior radius. Arms stout in their proximal portion, horizontally disposed or somewhat inclined upward. Judging by the articular facets, the arms were capable of considerable movement upward. Three anal plates within the cup, RA, x, and rt, supporting a stout ventral sac. The tegmen is low, composed in the main of small plates, and a madreporite is probably present. The stem is round and pierced by a pentagonal or pentalobate canal. The ornamentation of the cup consists of series of folds radiating from the centers of the plates.

Horizon.-So far as known, Vasocrinus is restricted to the Middle Devonian.

Genotype.-The genotype is Vasocrinus valens Lyon.

\section{VASOCRINUS VALENS LyOn}

The description of this species is based on the original specimens of Lyon's Figures $3 a$ and $3 b$, supplemented by three imperfect dorsal cups from the type locality.

Lyon's type specimen, Figure $3 a$, gives the following measurements :

Height of dorsal cup, $14 \mathrm{~mm}$.

Diameter of dorsal cup, $25 \mathrm{~mm}$. \pm (estimated).

Diameter of stem, $9 \mathrm{~mm}$.

Height of IBB, $3.5 \mathrm{~mm}$.

Height of $\mathrm{BB}, 7 \mathrm{~mm}$.

Width of $\mathrm{BB}$ (average), $9.4 \mathrm{~mm}$.

${ }^{3}$ Jaekel, Otto, Phylogenie und System der Pelmatozoen. Paleont. Zeitschr., vol. 3, Heft 1, p. $61,1918$. 
Height of RR (average), $6 \mathrm{~mm}$.

Breadth of RR (average), $13 \mathrm{~mm}$.

Breadth of arm facet (average), $6.5 \mathrm{~mm}$.

Specimen $3 b$ gives the following measurements:

Height of cup, $9 \mathrm{~mm}$.

Diameter of cup (ant. to post. IR), $15.5 \mathrm{~mm}$.

Diameter of stem, $4.6 \mathrm{~mm}$.

Height of IBB, $1.6 \mathrm{~mm}$.

Height of BB, $4.7 \mathrm{~mm}$.

Breadth of BB (average), $6 \mathrm{~mm}$.

Height of RR (average), $4.5 \mathrm{~mm}$.

Breadth of RR (average), $7.3 \mathrm{~mm}$.

Breadth of arm facet (average), $4.3 \mathrm{~mm}$.

It will be seen that the dorsal cup is low, with a breadth considerably in excess of the height. The infrabasals form a sharply defined ring with nearly vertical walls. Above, the sides of the cup diverge gently to about one-half the height of the basals. At this point the sides of the cup flare outward abruptly to give the maximum diameter of the cup at the lower margins of the arm facets. This form of the dorsal cup is characteristic of adult individuals. In the case of two large specimens that show the profile of the cup, other than speciman $3 a$ from which the description given above was made, there is a slight variation in the outline as given. In one specimen the cup is relatively lower. The infrabasal ring is less sharply defined, and the abrupt outward flare of the sides of the cup involves the greater part of the basals. In another specimen where the surface contours of the plates are better preserved than in the case of the type the outward flare appears to be somewhat less pronounced when the basals are viewed in profile, owing to the relatively high relief of the plates. As a matter of fact, the shape of the cup is about like that of the type. In specimen $3 b$, which is a much younger specimen, the relative proportions of height to breadth are almost exactly the same. Here, however, instead of the abrupt outward flare of the walls of the cup, the sides diverge more evenly from the top of the infrabasal ring.

The stem, judged by its impression on the infrabasals, was large, round in section, and traversed by a large pentagonal or obscurely pentalobate lumen. A dissociated fragment of column placed by Lyon with his specimens of Vasocrinus is pentagonal in section, with rounded angles. The lumen of this fragment, its size, and the character of the striae on the faces of the columnals are all very like the impressions of the proximal columnal as shown on the infrabasals. It may be, therefore, that the column was pentagonal in cross-section.

The infrabasals are subequal in size and together form a welldefined cylindrical ring or collar. The lower outer margins of the infrabasals are somewhat thickened, forming a rounded ridge. The basals are irregularly unequal in size. All except those adjacent to 
the posterior interradius are hexagonal in outline. The latter two are heptagonal. The r. post. B supports RA on its upper left shoulder. The post. B supports RA on its upper right shoulder and $\mathrm{x}$ on its superior face. On one specimen where the surface is somewhat better preserved than usual there are obscure radiating ridges passing over to the adjacent plates. The centers of the basals are elevated, the surface sloping gently to the upper and lower margins and much more abruptly to the sides. This results in well-defined depressions along the interbasal sutures. Low, broad ridges pass over to the radials, outlining these depressions. The radials vary considerably among themselves in size. The arm facets are large and in the adult specimens are nearly vertical in attitude or are inclined rery slightly upward. The amount of inclination varies in different rays. In the young specimen $3 b$ the upward inclination is somewhat more pronounced but not greatly so. The radial is pierced by an axial canal separate from the food-grove. On the surface of the arm facet to either side of the axial canal lies a short horizontally disposed articular facet. The surface of these facets is roughened by short vermicular ridges. The upper portion of the radial curves over and inward, forming a platform of appreciable width. Thus the radials from the exterior appear to be massive plates, whereas when cleared from the matrix they are found to be relatively thin. In the posterior interradius there are three anal plates within the cup. The radianal is fairly large, pentagonal, resting below on the post. and $\mathrm{r}$. post. $\mathrm{BB}$, laterally abutting on $\mathrm{r}$. post. $\mathrm{R}$ and $\mathrm{x}$ and supporting rt above. Anal $\mathrm{x}$ is somewhat larger than RA and supports two tube plates. It abuts laterally on 1 . post. R, RA, and rt, while below it rests on the post. $B$. The plates of the posterior interradius are traversed by radiating ridges that are really folds in the plates. These progressively become stronger as the tube proper is approached. Outside the proximal tube plates nothing is known of the structure of the tegmen. Specimen $3 b$ has one arm ossicle lying approximately in place. It is short and heavy and is pierced by an axial canal. On either side of the canal is a short articular facet, similar to those present on the main arm facet.

Horizon and locality.-Lyon cites his type specimen as from the quarries on Beargrass Creek, near Louisville, Ky. This would undoubtedly place the horizon as Onondaga (the Jeffersonville limestone of present local usage) of the Middle Devonian.

\section{VASOCRINUS SCULPTUS Lyon}

Of this, the second of Lyon's original species, a fair amount of material is now available for study. There are five dorsal cups in an excellent state of preservation. Three of these have the tegmens partially preserved, one has a fragment of column attached and two 
show the two proximal arm ossicles, in one case with the covering plates in place. In addition to the specimens coming from the type locality at Louisville, $\mathrm{Ky}$., there is one specimen from Columbus, Ohio.

Following are measurements made of the type specimen:

Height of dorsal cup, $7 \mathrm{~mm}$.

Breadth of dorsal cup (post. IR to ant. R), $12.7 \mathrm{~mm}$.

Diameter of stem, $4 \mathrm{~mm}$.

Height of IBB, $2.3 \mathrm{~mm}$.

Height of BB (average), $3.8 \mathrm{~mm}$.

Width of $\mathrm{BB}$ (average), $4 \mathrm{~mm}$.

Height of RR (average), $3.8 \mathrm{~mm}$.

Breadth of RR (average), $6 \mathrm{~mm}$.

Breadth of arm facet (average), $3 \mathrm{~mm}$.

Another specimen of average size gives the following set of measurements :

Height of dorsal cup, $9 \mathrm{~mm}$.

Breadth of dorsal cup (post. IR to ant. R), $16 \mathrm{~mm}$.

Diameter of stem, $5 \mathrm{~mm}$.

Height of IBB, $2.5 \mathrm{~mm}$.

Height of $\mathrm{BB}$ (average), $5 \mathrm{~mm}$.

Width of $\mathrm{BB}$ (average), $6 \mathrm{~mm}$.

Height of RR (average), $4 \mathrm{~mm}$.

Breadth of RR (average), $8 \mathrm{~mm}$.

Breadth of arm facet, $3 \mathrm{~mm}$.

The largest specimen seen has a breadth of 18 millimeters and a height of 9.5 millimeters.

Stripped of its surface ornamentation, the dorsal cup is broadly obconical in form, the sides diverging evenly to about the level of the radials and then flaring outward very slightly. With the ornamentation preserved, especially in the case of older individuals, the cup appears more rounded. In most specimens the cup is lower on the anterior side. This gives the theca a lopsided appearance which is very pronounced in the type specimen and is developed to a variable degree in different individuals.

The stem is round and at least in its proximal portion composed of alternate wide and narrow columnals. The lumen appears to bepentagonal in outline, with a slight suggestion of lobation.

The infrabasals are subequal in size. Their lower margins are somewhat produced, forming a lip. Near each lateral margin of an infrabasal is a sharp carina that runs from the lip across to the center of the adjacent basal. The basals are hexagonal in outline, with the exception of the posterior and right posterior, which are heptagonal in outline. The basals vary in size but apparently without a definite plan. The r. post. B supports RA on its upper left shoulder. The post. B supports RA on its upper right shoulder and 
$\mathrm{x}$ above. In addition to the pair of carinae connecting each basal and the infrajacent IBB, a high, sharp keel passes from the center of each basal to each adjacent plate. The radials vary considerably in size and proportions. The arm facets vary in attitude from vertical to being slightly inclined upward. The axial canal and food groove are confluent, although in cases where the plates are well preserved the axial canal is a narrow, deep channel sharply differentiated from the broader $V$-shaped groove above. In some cases it appears that the canal is arched over and separated from the groove above. In the anterior radial of one specimen the arm facet is greatly reduced in size, and it may well be that in this case no food groove was present. Below the groove and to either side is a triangular articulating facet with the apex pointing to the center. Below and between these facets is a well-defined triangular fossa, while above them is a pair of shallower fossae. The surfaces of the articulating facets as well as the margin of the arm facet are sharply crenulate. The upper margin of the radial curves inward, forming a platform around the margin of the tegmen. High, sharp keels pass from radial to radial at the lower level of the arm facets. Two similar keels likewise radiate from the arm facet to the infrajacent basals. Two brachials are preserved in one ray of each of two individuals. In the small specimen the brachial is constricted in the median portion, giving it a somewhat hour-glass shape. In the large specimen the brachial is almost cylindrical. In neither case is the second primibrach axillary. In the smaller specimen the arm covering plates are beautifully shown. They consist of a double series of high interlocking plates, there being three pairs to an ossicle.

There are three plates of the anal series incorporated in the cup. $\mathrm{RA}$ is unusually large in some specimens, being as large or larger than $\mathrm{x}$. RA is pentagonal in outline and bears the customary relations to the adjacent plates. Plate $\mathrm{x}$ supports two tube plates. The plates of the posterior interradius are traversed by series of plications similar to those on the remainder of the cup.

The tegmen is partially preserved in three specimens. It is made up of thin plates that apparently formed a weak structure. The outstanding feature of the tegmen is the presence in each specimen of a large knoblike madreporite. The openings of the canals penetrating the plate may clearly be seen in two of the specimens. In one specimen what appears to be part of the ventral sac is preserved. The sac is inclined upward slightly from the horizontal and curves gradually to the left. It is compressed laterally and increases gradually in size distad. Its point of inception is about on a level with the arm bases and on the right side of the posterior interradius. 
Very little of its structure can be made out. It was originally buried in a very hard fine-grained limestone, and great difficulty was had removing the closely adherent matrix.

The highly developed knifelike keels or carinae that form the characteristic ornamentation of the species and the character on which Lyon based his name are very interesting. In the type specimen, which is a fairly young individual, these ridges are worn down and show as slits, proving that at least in their basal portions the carinae are sharp folds in the thin plates. Dissociated plates and interiors also show this fact clearly. The higher portions of the carinae are solid.

Horizon and localities.-Lyon writes that his specimens were collected "about 5 feet beneath the Devonian black slate, and above the beds of Hydraulic cement stone, Jefferson County, and in the same geological position on the falls of the Ohio." This would place the species in the Beechwood limestone member of the Sellersburg limestone (approximately Hamilton). One lot of material bears a recent label of "Falls of the Ohio, Clark Co., Ind." Another silicified specimen with the infrabasals practically worn away but otherwise in an excellent state of preservation was collected by H. Hertzer in the State quarries at Columbus, Ohio. The horizon is stated to be Onondaga, but it is more probable that the specimen was collected from the Delaware limestone, of Hamilton and Marcellus age.

VASOCRINUS TURBINATUS, new species

In the Springer collection is a single theca of Vasocrinus labeled as coming from Louisville, Ky. The specimen is in a splendid state of preservation, the entire cup and the greater part of the tegmen being shown in great detail. It is unfortunate that the specimen can not be referred to $V$. valens, but its close relationship to that species permits the structures shown to be added to those of $V$. valens with the utmost confidence.

Following are measurements of the type and only known specimen:

Height of dorsal cup, $15 \mathrm{~mm}$.

Diameter of dorsal cup (ant. R. to Post. IR), $16.5 \mathrm{~mm}$.

Diameter of stem, $5.4 \mathrm{~mm}$.

Height of IBB, $2.6 \mathrm{~mm}$.

Height of $\mathrm{BB}, 5.8 \mathrm{~mm}$.

Breadth of $\mathrm{BB}$ (average), $6.3 \mathrm{~mm}$.

Height of RR (average), $4.1 \mathrm{~mm}$.

Breadth of RR (average), $7 \mathrm{~mm}$.

Breadth of arm facet (average), $4.5 \mathrm{~mm}$.

As will be noted from the measurements, the height and breadth of the dorsal cup are approximately equal. In form the cup is sub- 
turbinate, the sides diverging evenly from the infrabasal circlet to the arm bases, with a slight outward flare at about the top of the basals. The tegmen is low.

The infrabasals form a fairly distinct ring which is, however, not as sharply set off from the remainder of the cup as in the case of V. valens. The lower outer margins of the infrabasals are somewhat produced, forming a low rounded interrupted ridge surrounding the base. The basals are variable in size. The posterior and right posterior basals are heptagonal in outline. The $\mathrm{r}$. post. B supports RA on its upper left shoulder. The post. B supports RA on its upper right shoulder and plate $\mathrm{x}$ above. The surface of the basals is most elevated near the center of the plate. From this point rounded ridges radiate to the adjacent plates, forming depressed areas along the interbasal sutures as in $V$. valens. In addition to these larger ridges there are inconspicuous folds or ridges crossing from the basals to the radials. The radials are somewhat variable in size. At about che upper level of the arm facets the radials bend over and inward, forming a narrow shelf. The arm facets are directed slightly upward. The radials are pierced by axial canals, which occupy a median position on the arm facets. To either side of the axial canal is a sharply defined articulating facet. $\mathrm{RA}$ is large, resting below on the post. and r. post. BB, abutting laterally on $r$. post. $R$ and $x$, and supporting rt above. Anal $\mathrm{x}$ is still larger and supports two tube plates above. The tegmen is low and is somewhat depressed at each interradius except the posterior, giving it a somewhat lobate appearance. The plates are comparatively heavy, forming a fairly strong rigid tegmen. With the breaking off of the ventral tube a few of the tegminal plates have been lost. The surface of some of the plates has been slightly weathered, giving three or four of them a somewhat roughened and pitted appearance. It is not possible, therefore, definitely to state whether a madreporite is present or not. The stem as shown by the impression of the proximal columnal on the infrabasals is round and pierced by a fairly large pentalobate axial canal. But one brachial is preserved. This is short, stout, and somewhat constricted in its median portion. It is traversed by an axial canal distinct from the food groove. As shown in its proximal portion, the food groove is covered by a series of highly arched covering plates.

This species differs from $V$. valens chiefly in the shape and proportions of the dorsal cup. The straight sides of $V$. turbinatus gradually diverging from the base to the arm facets give it a habit quite at variance with the relatively low rapidly expanding cup of $V$. valens.

Horizon and locality.-The specimen was found in a tray with an assortment of crinoids labeled as coming from Louisville, Ky. As 
several of the other specimens bore Lyon's label, it is probable that the specimen was acquired with the Lyon collection. The close relationship of $V$. turbinatus to $V$. valens makes it probable that it came from the same horizon; that is, the Jeffersonville limestone (Onondaga).

Having reestablished the genus Vasocrinus on the foundation originally laid by Lyon, it remains to consider the status of Cyathocrinus hexadactylus Lyon and Casseday. Wachsmuth and Springer ${ }^{4}$ recognized the identity of Hall's Cyathocrinus lyoni with Cyathocrinus hexadactylus Lyon and Casseday. They state "Lyon's name has precedence, but being specifically as well as generically incorrect, we adopt Professor Hall's later name." Their action, in those days of loosely applied rules of nomenclature, is not more to be censured than the rather naive mistake of Lyon and Casseday in taking the anal $\mathrm{x}$ for a radial and the vertical median range of plates of the ventral sac as an arm. Hence came the "specifically incorrect" hexadactylus which we must adopt. Weller ${ }^{5}$ has recognized the validity of Lyon and Casseday's name and places Cyathocrinus lyoni Hall in proper synonymy. This species, the structure of which has long been considered typical of Vasocrinus, can not be placed in any described genus. It is therefore made the type of a new genus, Pellecrinus, and a brief generic diagnosis is here given.

\section{PELLECRINUS, new genus}

Dorsal cup low, broad, composed of relatively thin plates. Radial facet horseshoe-shaped, about one-half the width of the radial. Two anal plates in the dorsal cup, rarely one: RA quadrangular, sometimes wanting; $\mathrm{x}$ heptagonal, approximately as large as the radials and supporting three tube plates. Ventral sac stout, reaching about one-half the height of the arms. Reaching to about one-half the height of the ventral sac on the posterior side is a median line of heavy plates. The remainder of this side is made up of fairly heavy plates of smaller size. The sides and anterior portion of the sac is composed of thinner plates, most of which show axial folds. The anal opening lies at the apex of the ventral sac. The arms are long, relatively slender, and bifurcate once. The third primibrach is the axillary in all known species except one, when there are but two primibrachs. On each ramus ramuli are borne on alternate sides. In the known species the ramuli are borne by each second secundibrach. The ramuli themselves on the type species bear subramuli. The stem is large, round in section, and composed of alternate wide

\footnotetext{
${ }^{4}$ Wachsmuth, Charles, and Springer, Frank, Revision of the Palaeocrinoidea, pt. 1, p. 96 (321), 1879.

${ }^{5}$ Weller, Stuart, A bibliographic index of North American Carboniferous invertebrates: U. S. Geol. Survey Bull. 153, 1898.
} 
and narrow columnals. It is perforated by a small obscurely pentalobate canal.

Genotype-Cyathocrinus hexadactylus Lyon and Casseday (Cyathocrinus Tyoni Hall).

Geological range.-The typical forms of the genus occur in the lower Carboniferous (Mississippian), but undescribed species from the high Middle Devonian have been examined that may be referable to the genus.

\section{EXPLANATION OF PLATES}

Plate 1

The figures within the dotted frame (fig. 10) are photographic copies of Lyon's original illustrations. The numbers $3-3 e$ are the same as Lyon's original numbers.

\section{Vasocrinus sculptus Lyon}

Fig. 1. Posterior view of holotype.

FIG. 2. Basal view of holotype.

Fig. 3. Enlargement $\times 3$ of portion of dorsal cup showing detail of weathered plate folds.

Fig. $10(3 c, 3 d, 3 e)$. Lyon's original figures of the holotype.

Middle Devonian, Sellersburg limestone (of Hamilton age), Falls of the Ohio, Louisville, Ky.

\section{Vasocrinus valens Lyon}

Figs. 4, 5, 6. Basal, posterior, and left anterior views of specimen referred by Lyon to $V$. sculptus, but here considered as a cotype of $V$. valens.

FIG. $10(3 b)$. Lyon's figure of the same specimen.

Figs. 7, 8, 9. Lateral, basal, and ventral view of Lyon's type of $V$. valens, showing the imperfect cup.

FIg. $10(3 a)$. Lyon's original figure of this specimen.

FIG. 10 (3). Lyon's generic diagram cited as $V$. valens, evidently a composite of his figures $3 a$ and $3 b$.

Middle Devonian, Jeffersonville limestone (of Onondaga age), quarries on Beargrass Creek, near Louisville, Ky.

\section{Plate 2}

Vasoorimus turbinatus, new species

Figs. 1, 2, 3. Posterior, tegminal, and anterior views of the holotype.

FIG. 4. Diagram of this specimen, which serves as a generic diagram for Vasocrinus.

Middle Devonian, Jeffersonville limestone (of Onondaga age), Louisville, Ky.

\section{Vasocrinus sculptus Lyon}

FIg. 5. Left anterior view $\times 2$ of a small specimen showing the madreporite and two primibrachs with their covering plates. The horizontally disposed structure back of the arm base and to the right is the ventral sac.

Fig. 6. Basal view of large specimen showing two primibrachs in one ray.

Figs. 7, 8, 9, 10. Posterior, tegminal, left posterior interradial and basal views of another specimen.

Middle Devonian, Sellersburg limestone (Hamilton), Falls of the Ohio, Louisville, Ky. 


\section{$2 \mathrm{BHL}$ Biodiversity Heritage Library}

Kirk, Edwin. 1929. "The fossil crinoid genus Vasocrinus Lyon." Proceedings of the United States National Museum 74(2760), 1-16. https://doi.org/10.5479/si.00963801.74-2760.1.

View This Item Online: https://www.biodiversitylibrary.org/item/32497

DOI: https://doi.org/10.5479/si.00963801.74-2760.1

Permalink: https://www.biodiversitylibrary.org/partpdf/28961

\section{Holding Institution}

Smithsonian Libraries

\section{Sponsored by}

Smithsonian

\section{Copyright \& Reuse}

Copyright Status: NOT_IN_COPYRIGHT

Rights: https://www.biodiversitylibrary.org/permissions/

This document was created from content at the Biodiversity Heritage Library, the world's largest open access digital library for biodiversity literature and archives. Visit BHL at https://www.biodiversitylibrary.org. 